Check for updates

Cite this: Nanoscale Adv., 2019, 1, 219

\title{
Impact of humic acid on the fate and toxicity of titanium dioxide nanoparticles in Tetrahymena pyriformis and zebrafish embryos $\uparrow$
}

\author{
Govind Sharan Gupta, Krupa Kansara, + Helly Shah, Ruchi Rathod, Drishti Valecha, \\ Saurabh Gogisetty, Pankti Joshi and Ashutosh Kumar (D)*
}

\begin{abstract}
The extensive usage of titanium dioxide $\left(\mathrm{TiO}_{2}\right)$ nanoparticles in daily usage products have increased their release into the environment. The present study has attempted to investigate the behaviour of titanium dioxide $\left(\mathrm{TiO}_{2}\right)$ nanoparticles in different experimental buffers in the presence of humic acid. Also, the effect of $\mathrm{TiO}_{2}$ nanoparticles was assessed in different aquatic organisms with and without the presence of humic acid. The results demonstrate that humic acid increases the dispersion of $\mathrm{TiO}_{2}$ nanoparticles via its adsorption on the surface of the nanoparticles, mainly due to electrostatic interactions. The maximum aggregation was observed in the zebrafish growth medium (E3 medium) even in the presence of humic acid. The intensity of $\mathrm{TiO}_{2}$ nanoparticle sedimentation was observed in the order: $\mathrm{E3}$ media > Dryl's buffer > MilliQ water. Interestingly, the ecotoxicity results for Tetrahymena pyriformis and Danio rerio showed that the presence of humic acid reduces the toxicity of $\mathrm{TiO}_{2}$ nanoparticles.
\end{abstract}

Received 20th June 2018

Accepted 18th July 2018

DOI: 10.1039/c8na00053k

rsc.li/nanoscale-advances

of these studies have been performed under laboratory condi-

\section{Introduction}

The advancement in the applications of nanotechnology from biotechnology to agriculture has increased nanoparticle (NP) emissions in the environment. NPs, after being released into the surroundings, eventually reach aquatic systems and pose a risk to the ecosystem at individual, population and community levels. ${ }^{1}$ The estimated release of NPs in the environment has been predicted to be $21 \%$ to aquatic systems, $17 \%$ to soils, $2 \%$ to air and $60 \%$ to landfills. ${ }^{2,3}$ The reactivity of the nanoparticles is mainly due to their quantum size and large surface area to volume ratio, which can be diminished by their homo or hetero-aggregations in the presence of biotic and abiotic factors. ${ }^{4-7}$

Titanium dioxide $\left(\mathrm{TiO}_{2}\right)$ NPs are one of the most abundantly used in consumer products such as cosmetics, paints, food additives, pharmaceuticals, electronics and textiles as well as in construction and waste-water treatment and have started appearing in the aquatic environment. ${ }^{8}$ Therefore, it is imperative to understand their environmental interactions and safety for aquatic organisms. Earlier studies have shown that $\mathrm{TiO}_{2} \mathrm{NPs}$ can cause toxic effects to different aquatic organisms such as bacteria, protozoans, algae, crustaceans and zebrafish. ${ }^{9-13}$ Most

Biological \& Life Sciences, School of Arts \& Sciences, Ahmedabad University, Central Campus, Navrangpura, Ahmedabad, 380009, Gujarat, India. E-mail: ashutosh. kumar@ahduni.edu.in

$\dagger$ Electronic supplementary information (ESI) available. See DOI: $10.1039 / \mathrm{c} 8 \mathrm{na00053 \textrm {k }}$

\$ Authors contributed equally. tions, without assessing the influence of either biotic or abiotic environmental factors.

Humic acid is one of the most abundant and widespread naturally occurring organic materials in the environment. ${ }^{17} \mathrm{It}$ exists naturally in soils, peats, oceans and fresh water representing about $25 \%$ of the carbon on earth and $50-75 \%$ of the carbon in water. ${ }^{18}$ It plays a crucial role in the speciation, transport and deposition of a variety of materials ranging from metal ions to lipophilic compounds. ${ }^{19}$ The study of nanoparticles binding to naturally abundant organic matter is of primary importance to understanding the safety of nanoparticles in aquatic systems.

The model organisms used for this study were selected from two major groups: unicellular eukaryotes (ciliated protozoan, Tetrahymena pyriformis) and multicellular eukaryotes (zebrafish, Danio rerio). Tetrahymena is a unicellular, eukaryotic and free living protozoan and has been extensively used as a model organism for safety assessments., ${ }^{\mathbf{4 , 2 1}}$ It is a filter feeder organism that reduces the bacterial population and also controls the bioavailability of particulate iron in the environment. ${ }^{21,22}$ It connects prokaryotes to eukaryotes in the food chain and plays a significant ecological role by controlling harmful bacterial populations, nutrient cycling and iron bioavailability. Danio rerio is another important vertebrate research model due to its numerous properties such as easy maintenance, high fecundity, rapid development, transparent embryos, being a significant link in the food web, availability of a complete genome sequence and genetic similarity with humans $(\sim 70 \%)^{23,24}$ Early stage embryos of zebrafish have 
already been used extensively in the high throughput assessment of eco-nano-safety. ${ }^{25}$

It has now been very well demonstrated that NPs interact with natural organic matter (NOM), exopolymeric substances (EPS) and clay particles upon entry into the aquatic environment. ${ }^{\mathbf{4 , 1 4 , 1 5}}$ Among these factors NOM such as humic acid (HA) is known to influence the stability of NPs in the aquatic system due to adsorption on the surface of the NPs. ${ }^{16}$ However, the consequent effects of HA on the toxicity of NPs to aquatic organisms have not been well studied. Therefore, the present study was designed to investigate the potential effect of HA on the stability of $\mathrm{TiO}_{2}$ nanoparticles in different experimental buffers and their toxicity to a range of aquatic model organisms such as ciliated protozoan (Tetrahymena pyriformis) and early stage embryos of zebrafish (Danio rerio).

\section{Materials and methods}

\subsection{Chemicals and materials}

A mixed rutile and anatase phase $\mathrm{TiO}_{2}$ nanopowder (catalogue no. RN-PL-TiO-P25-50g) was procured commercially from Reinste Nano Ventures Pvt. Ltd. (Noida, India). HA powder (CAS no. 6811-04-4) was procured from HiMedia (Mumbai, India). All other chemicals were analytical reagent grade and procured from HiMedia (Mumbai, India).

\subsection{Model organisms and culture conditions}

2.2.1. Zebrafish husbandry. An Assam wild-type strain of zebrafish was a kind gift from CSIR-IGIB, New Delhi, India. The fishes were maintained under laboratory conditions at Ahmedabad University (Ahmedabad, Gujarat, India). The fishes were grown as per the standard protocols of the Zebrafish Information Network (ZFIN). Briefly, the male and female zebrafish were kept separately in a $20 \mathrm{~L}$ aquarium filled with artificial freshwater prepared by dissolving $60 \mathrm{mg} \mathrm{L}^{-1}$ of sea salt (Red Sea, India) in distilled water $\left(\mathrm{dH}_{2} \mathrm{O}\right)$. The temperature was maintained at $26-28{ }^{\circ} \mathrm{C}$ with a $14 \mathrm{~h}$ light/10 h dark cycle. The adult zebrafish were fed with live brine shrimp (Artemia) thrice a day. Zebrafish eggs were collected alternately in the morning by setup breeding with a ratio of three females to two males in the breeding chamber. The eggs were collected into sterile Petriplates filled with egg water and were raised at $28.0 \pm 1.0^{\circ} \mathrm{C}$ in a BOD incubator (MIR-154, Panasonic, Japan). The embryos were further transferred into $\mathrm{E} 3$ medium (5 mM NaCl, $0.17 \mathrm{mM}$ $\mathrm{KCl}, 0.33 \mathrm{mM} \mathrm{CaCl} 2$ and $0.33 \mathrm{mM} \mathrm{MgSO}_{4}$ and the $\mathrm{pH}$ was adjusted to 7.0-7.2) before the experiments.

2.2.2. Protozoan culture. Tetrahymena pyriformis was procured from Carolina Biological Supply Co. (Burlington, USA). The cells were grown in a BOD incubator at $22^{\circ} \mathrm{C}$ under dark conditions by following the protocol suggested by Gupta et al. (2017). ${ }^{4}$ The overnight grown culture of Tetrahymena was used in the experiments. The cells were harvested by centrifugation $\left(710 \times g\right.$ for $5 \mathrm{~min}$ at $\left.4{ }^{\circ} \mathrm{C}\right)$ and subsequent washing was done with Dryl's buffer ( $2 \mathrm{mM}$ sodium citrate, $2 \mathrm{mM} \mathrm{NaH} \mathrm{PO}_{4}$, $1 \mathrm{mM} \mathrm{Na}_{2} \mathrm{HPO}_{4}, 1.5 \mathrm{mM} \mathrm{CaCl}_{2}, \mathrm{pH}$ 6.9-7.0). The Tetrahymena cells were starved for 16-24 h in Dryl's buffer before using for the experiment. The number of Tetrahymena cells per $\mathrm{mL}$ was counted by using haemocytometer under an optical microscope. The cells were fixed with $0.01 \%$ of neutral formalin before counting.

\subsection{Preparation and characterization of $\mathrm{TiO}_{2}$ nanoparticles}

A stock suspension of $\mathrm{TiO}_{2}$ nanoparticles $\left(1000 \mu \mathrm{g} \mathrm{mL} \mathrm{m}^{-1}\right)$ was prepared in sterile MilliQ water using sonication at $30 \%$ amplitude and 30 watts for 10 min using a probe sonicator (Sonics Vibra Cell, Sonics \& Material Inc., New Town, USA). Subsequently, the suspension was diluted to $50 \mu \mathrm{g} \mathrm{mL} \mathrm{m}^{-1}$ and used for characterization of size, surface charge and optical properties. The purity of the $\mathrm{TiO}_{2}$ nanopowder was determined using energy-dispersive X-ray spectroscopy (EDS) coupled with scanning electron microscopy (SEM).

The hydrodynamic size and zeta potential of the $\mathrm{TiO}_{2}$ nanoparticles were determined using dynamic light scattering (DLS) and phase analysis light scattering (PALS) using a Zetasizer Nano-ZS equipped with a $4.0 \mathrm{~mW}, 633 \mathrm{~nm}$ laser. The actual size distribution was further validated using transmission electron microscopy (TEM). The wavelength of the maximum emission of the $\mathrm{TiO}_{2}$ NPs was determined using UV-Vis spectroscopy, BioTek Synergy HT, USA.

\subsection{Motivation for the selection of nanoparticle concentration}

The fate experiments of the nanoparticles were conducted at a concentration of $50 \mu \mathrm{g} \mathrm{mL}{ }^{-1}$ due to its optimum detection in all the characterization techniques used in the measurement. In the biological experiments, the lowest concentration of $\mathrm{TiO}_{2}$ nanoparticles $\left(1 \mu \mathrm{g} \mathrm{mL} \mathrm{m}^{-1}\right)$ was selected as per the predicted concentration available in the environment. ${ }^{26}$ Meanwhile, a range of higher concentrations $\left(10,50,100 \mu \mathrm{g} \mathrm{mL}^{-1}\right)$ were selected to obtain the dose dependent response relationship.

\subsection{Fate of nanoparticles in the experimental buffers}

Dryl's buffer and E3 medium were exclusively used in the safety assessment of the NPs for protozoans and zebrafish embryos, respectively. HA was added in these media at a concentration of $10 \mu \mathrm{g} \mathrm{mL}{ }^{-1}$, to mimic the environmental conditions. ${ }^{28}$ The fate of the NPs was determined by measuring aggregation, surface modification and sedimentation of the nanoparticles in the presence or absence of HA. The experiments were put into seven different groups as follows:

Group 1: $\mathrm{TiO}_{2}$ NPs $\left(50 \mu \mathrm{g} \mathrm{mL}^{-1}\right)$ in MilliQ water (control)

Group 2: $\mathrm{TiO}_{2}$ NPs $\left(50 \mu \mathrm{g} \mathrm{mL}^{-1}\right)$ in Dryl's buffer

Group 3: $\mathrm{TiO}_{2}$ NPs $\left(50 \mu \mathrm{g} \mathrm{mL}^{-1}\right)$ in E3 media

Group 4: HA $\left(10 \mu \mathrm{g} \mathrm{mL}{ }^{-1}\right)$ in MQ water, Dryl's buffer and E3 media (control)

Group 5: $\mathrm{TiO}_{2}$ NPs $\left(50 \mu \mathrm{g} \mathrm{mL}^{-1}\right)+\mathrm{HA}\left(10 \mu \mathrm{g} \mathrm{mL} \mathrm{m}^{-1}\right)$ in MilliQ water

Group 6: $\mathrm{TiO}_{2}$ NPs $\left(50 \mu \mathrm{g} \mathrm{mL} \mathrm{m}^{-1}\right)+\mathrm{HA}\left(10 \mu \mathrm{g} \mathrm{mL}^{-1}\right)$ in Dryl's buffer

Group 7: $\mathrm{TiO}_{2}$ NPs $\left(50 \mu \mathrm{g} \mathrm{mL}^{-1}\right)+\mathrm{HA}\left(10 \mu \mathrm{g} \mathrm{mL}^{-1}\right)$ in E3 media 
The $\mathrm{pH}$ of all the groups remains the same between 6.7 and 6.9 throughout the experiment (Table S1 $\dagger$ ).

2.5.1. Aggregation of NPs. The aggregation of the NPs in the different groups was determined by measuring the hydrodynamic diameter $\left(D_{\mathrm{h}}\right)$ of the NPs using DLS. The aggregation pattern was followed for $96 \mathrm{~h}(0,0.5,1,2,3,4,24,48$ and $96 \mathrm{~h})$. The increase in the size of the NPs with respect to time and experimental media will enable prediction of the aggregation intensity of the $\mathrm{TiO}_{2}$ NPs.

2.5.2. Electro-kinetic interactions of NPs with HA. The electro-kinetic changes in the suspensions of $\mathrm{TiO}_{2} \mathrm{NPs}_{\text {in }}$ all the groups were measured by determining the zeta potential using PALS. The difference in the surface charge of the NPs allowed the determination of the intensity of the electrostatic interactions between the NPs and HA.

2.5.3. Adsorption of HA on the NPs. The adsorption of HA on the $\mathrm{TiO}_{2}$ NPs in MQ water and experimental buffers was investigated by measuring the fluorescence intensity of $\mathrm{HA}$ at a characteristic wavelength $(350 \mathrm{~nm})$ using fluorescence spectroscopy (model no. G9800A Fluorescence, Cary Eclipse, Agilent Technologies, USA). The samples for analysis were prepared by settling the NPs by centrifugation at $3220 \times g$ for $30 \mathrm{~min}$. The colour of the settled NPs was also captured using a digital camera.

2.5.4. Sedimentation of NPs. The sedimentation of the NPs in the different groups was determined by measuring a time dependent change in the absorbance of the $\mathrm{TiO}_{2}$ NPs at a specific wavelength $(320 \mathrm{~nm})$. The absorbance was recorded in a quartz cuvette with a $1 \mathrm{~cm}$ optical path length filled with a $1 \mathrm{~mL}$ suspension of $\mathrm{TiO}_{2}$ NPs. The absorbance of the $\mathrm{TiO}_{2} \mathrm{NPs}$ was recorded using UV-Vis spectroscopy at $320 \mathrm{~nm}$ at an initial $\left(A_{0}\right)$ and final $\left(A_{t}\right)$ time point. A breakthrough curve was plotted for $A_{t} / A_{0}$ as the $y$-axis against time (h) as the $x$-axis.

\subsection{Ecotoxicity experiments}

2.6.1. Zebrafish embryo toxicity assays. All the experiments were conducted in six well microtiter plates (Corning, NY, USA). Each well contained 15 embryos ( $4 \mathrm{~h}$ post fertilization) in $4 \mathrm{~mL}$ of E3 medium. The concentration of $\mathrm{TiO}_{2}$ NPs in the treatment groups was in the range of $1,10,50$ and $100 \mu \mathrm{g} \mathrm{mL} L^{-1}$. The embryos were exposed for $48 \mathrm{~h}$ to $\mathrm{TiO}_{2}$ NPs under a 10/14 $\mathrm{h}$ dark/light cycle in a BOD incubator at $22{ }^{\circ} \mathrm{C}$. The experiments were conducted in four groups:

Group 1: embryos in E3 medium (control)

Group 2: embryos + HA $\left(10 \mu \mathrm{g} \mathrm{mL}^{-1}\right)$ in E3 medium (control)

Group 3: embryos $+\mathrm{TiO}_{2} \mathrm{NPs}\left(1,10,50\right.$ and $\left.100 \mu \mathrm{g} \mathrm{mL}{ }^{-1}\right)$ in

E3 medium

Group 4: embryos $+\mathrm{TiO}_{2}$ NPs $\left(1,10,50\right.$ and $\left.100 \mu \mathrm{g} \mathrm{mL}^{-1}\right)+$ $\mathrm{HA}\left(10 \mu \mathrm{g} \mathrm{mL} \mathrm{m}^{-1}\right)$ in E3 medium

Embryos were observed under a stereo-zoom microscope to determine the mortality at $0,1,3,4,24,42,44$, and $48 \mathrm{~h}$. The embryos with a ruptured yolk were considered dead. The delay
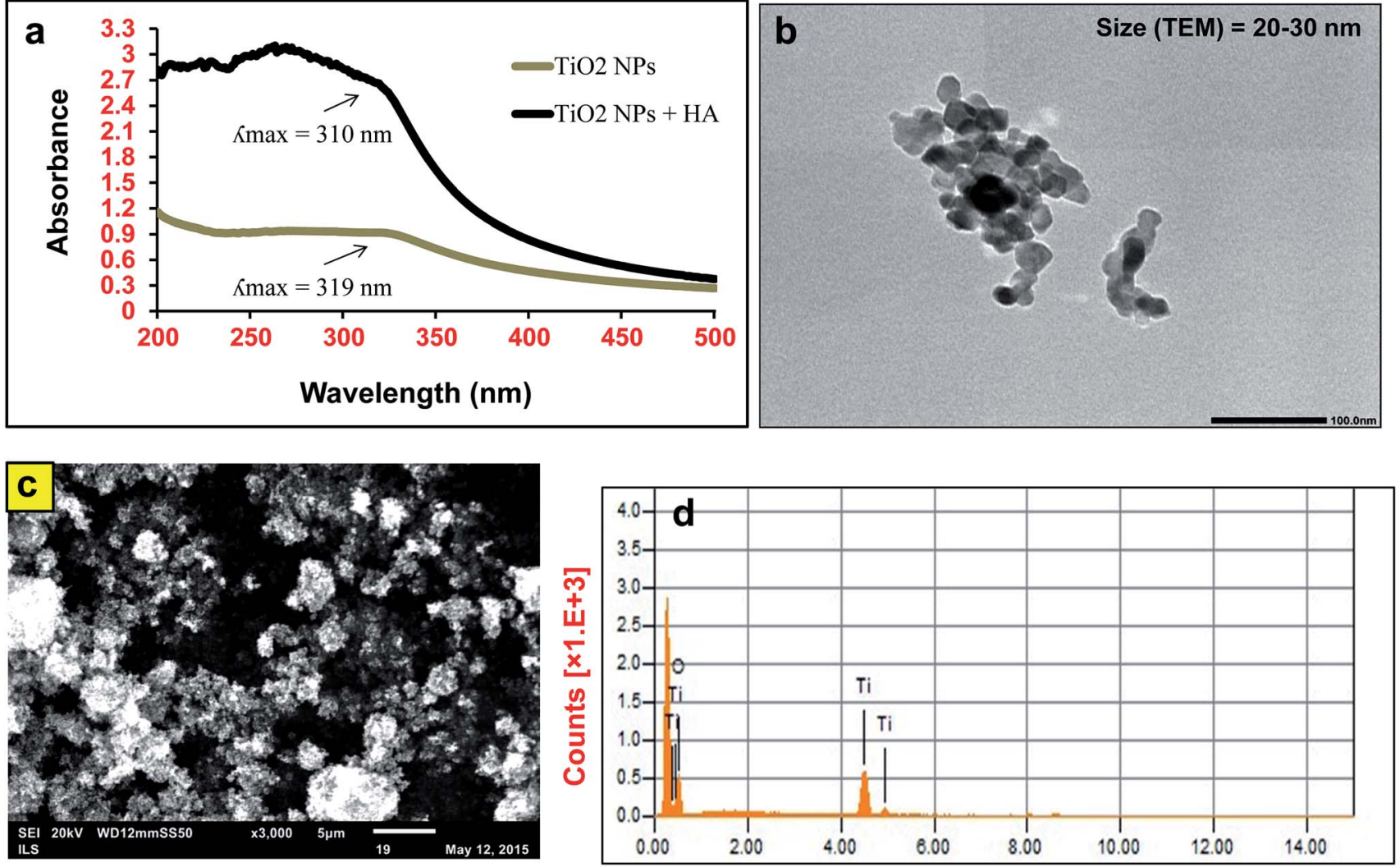

keV

Fig. 1 Characteristics of $\mathrm{TiO}_{2}$ nanoparticles $\left(50 \mu \mathrm{g} \mathrm{mL}^{-1}\right)$ in MilliQ water in the presence and absence of humic acid (10 $\left.\mu \mathrm{g} \mathrm{mL}{ }^{-1}\right)$. (a) UV-Vis spectroscopy, (b) TEM, (c) SEM and (d) EDS spectra. 
in hatching time in the treated groups compared to the controls was also recorded.

2.6.2. Tetrahymena viability assay. The experiments were conducted in 6 well microtiter plates (Corning, NY, USA). Each well contained $10^{4}$ Tetrahymena cells per $\mathrm{mL}$ in Dryl's buffer. Tetrahymena cells were exposed to $\mathrm{TiO}_{2}$ NPs $(1,10,50$ and 100 $\left.\mu \mathrm{g} \mathrm{mL} \mathrm{m}^{-1}\right)$ in the presence and absence of HA $\left(10 \mu \mathrm{g} \mathrm{mL}{ }^{-1}\right)$ for $24 \mathrm{~h}$ in BOD incubation under dark conditions at $22{ }^{\circ} \mathrm{C}$. The viability of the cells was determined using a direct counting method as described by Gupta et al. (2017). ${ }^{4}$ Briefly, the number of dead cells in the total number of cells in a $20 \mu \mathrm{L}$ sample was counted under an optical microscope (Model CETi; Medline Scientific Ltd., Bangalore, India) at $400 \times$ magnification. The non-motile cells and cells with abnormal morphology were considered dead cells. The viability (\%) was calculated using the formula:

Viability $(\%)=[($ total cells - dead cells $) /$ total cells $] \times 100$

\subsection{Statistical analysis}

All the experiments were performed in triplicate, and the results are expressed as the mean \pm standard error (SE) of the mean. The statistical analysis was carried out using Microsoft ${ }^{\circledR}$ Excel 2007 and GraphPad Prism® version 3.02.

\section{Results and discussion}

\subsection{Characteristics of $\mathrm{TiO}_{2} \mathrm{NPs}$}

The SEM observation and consequent elemental analysis of the $\mathrm{TiO}_{2}$ nanopowder using EDS showed titanium peaks in the spectra with no other impurities. The TEM observation demonstrated a heterogeneous dispersion of $\mathrm{TiO}_{2}$ NPs with a range of particle sizes between 20 and $30 \mathrm{~nm}$ (Fig. 1). The hydrodynamic size $\left(D_{\mathrm{h}}\right)$ and zeta potential of the $\mathrm{TiO}_{2} \mathrm{NPs}$ in MilliQ water were $333 \mathrm{~nm}$ and $-22 \mathrm{mV}$, respectively. The $D_{\mathrm{h}}$ of the $\mathrm{TiO}_{2}$ NPs decreased to $268 \mathrm{~nm}$ after addition of HA, while the zeta potential of the suspension increased to $-29 \mathrm{mV}$. UV-Vis spectroscopy analysis of the $\mathrm{TiO}_{2} \mathrm{NP}$ suspension in MilliQ water $\left(50 \mu \mathrm{g} \mathrm{mL}^{-1}\right)$ showed an absorption maximum $\left(\lambda_{\text {max }}\right)$ at $\sim 320 \mathrm{~nm}$ (Fig. 1a), which was shifted slightly towards a lower wavelength of $310 \mathrm{~nm}$ after addition of HA $\left(10 \mu \mathrm{g} \mathrm{mL} \mathrm{m}^{-1}\right)$.

\subsection{Aggregation and sedimentation of $\mathrm{TiO}_{2} \mathrm{NPs}$}

An increase in the size of the $\mathrm{TiO}_{2}$ NPs in Dryl's buffer and E3 medium was observed with respect to MQ water (Fig. 2). The size of bare $\mathrm{TiO}_{2}$ NPs in Dryl's buffer increased with time from $589 \pm 135 \mathrm{~nm}$ at $0 \mathrm{~h}$ to more than $1270 \pm 25 \mathrm{~nm}$ at $96 \mathrm{~h}$. The presence of citrate ions in Dryl's buffer provided stability to the NPs in the suspension at the initial time point due to their adsorption on the surface. Meanwhile, at later stages these NPs start aggregating due to dominant hydrophobic interactions between the $\mathrm{TiO}_{2}$ NPs. The addition of HA to the suspension of $\mathrm{TiO}_{2}$ NPs in Dryl's buffer reduces the size $\left(D_{\mathrm{h}}=249 \pm 25 \mathrm{~nm}\right)$ and influences the stability of the suspension as measured for

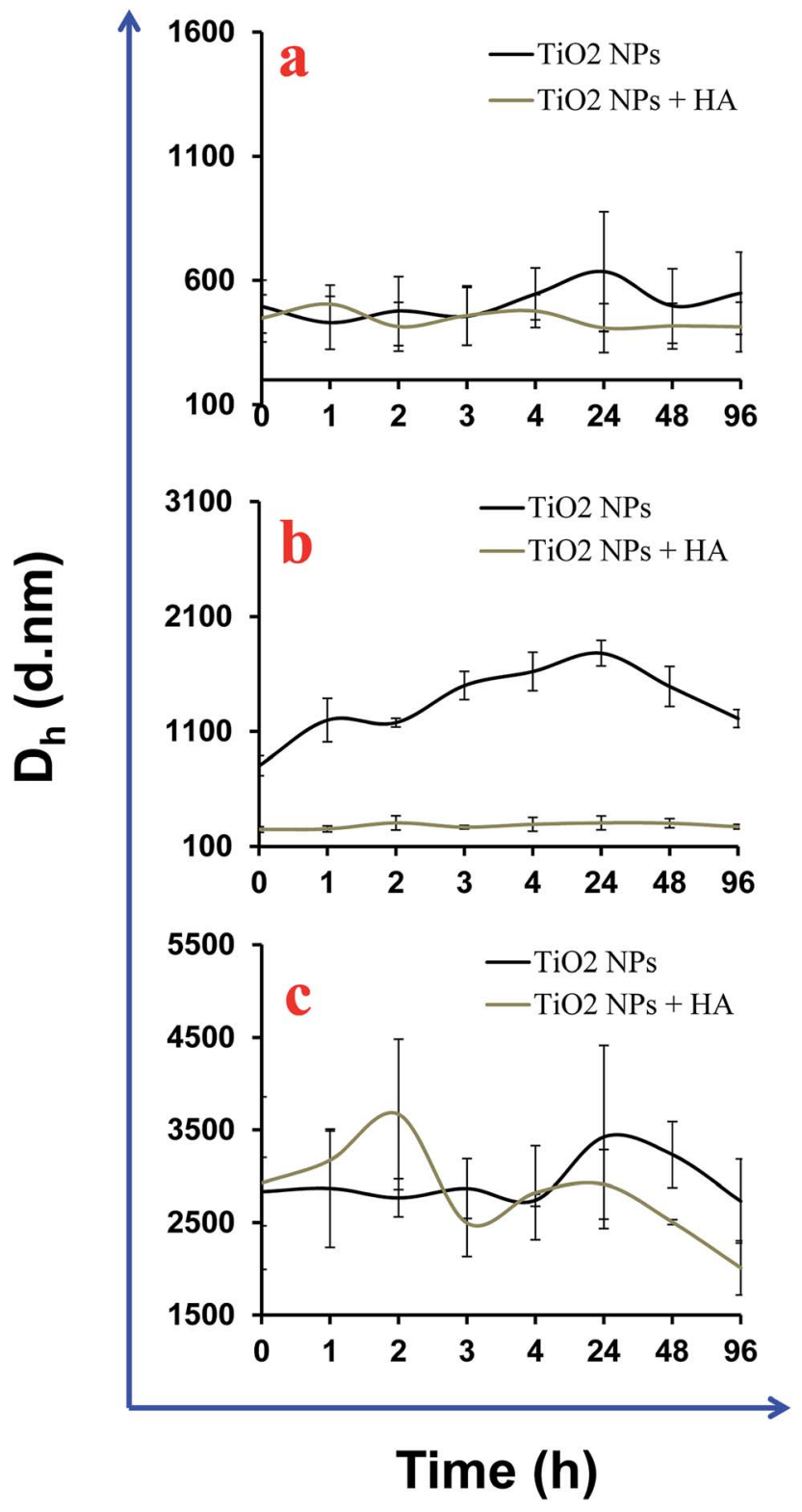

Fig. 2 Aggregation of $\mathrm{TiO}_{2}$ nanoparticles $\left(50 \mu \mathrm{g} \mathrm{mL}^{-1}\right)$ in different experimental buffers in the presence and absence of humic acid $(\mathrm{HA})$ $\left(10 \mu \mathrm{gL}^{-1}\right.$ ). (a) MQ water, (b) Dryl's buffer and (c) E3 medium.

$96 \mathrm{~h}\left(D_{\mathrm{h}}=257 \pm 9 \mathrm{~nm}\right)$. The increase in the stability of the $\mathrm{TiO}_{2}$ NPs was due to the strong negative charge intensity on the surface of the NPs generated after adsorption of HA, leading to strong electrostatic repulsion.

Furthermore, rapid aggregation of $\mathrm{TiO}_{2}$ NPs was observed in the E3 medium due to the presence of a high mineral content ( $\mathrm{Na}, \mathrm{K}, \mathrm{Mg}$ and $\mathrm{Ca}$ ) to support the survival of the zebrafish embryos. The initial size of the $\mathrm{TiO}_{2}$ NPs in the E3 medium was $\sim 2900 \mathrm{~nm}$ and this further increased up to $3400 \mathrm{~nm}$. Surprisingly, the addition of HA to the E3 medium influences the size of the NPs up to $3500 \mathrm{~nm}$ in the initial $2 \mathrm{~h}$, which then further reduces to $1800 \mathrm{~nm}$ at later time points (Fig. 2c). This could be due to delayed adsorption of HA on the surface of the NPs. A delay in adsorption of HA on NP surfaces could be possible due 
to the presence of inorganic ions $\left(\mathrm{SO}_{4}{ }^{2-}, \mathrm{Cl}^{-}\right)$in the media that shielded the NP surface and prevented rapid binding. The polydispersity index of the NPs in E3 medium was high due to greater heterogeneity in the sizes of the NP clusters that also influences the inter-assay variations in the experiments (Table S2 $\dagger$ ). Moreover, the generation of large clusters of NPs in the test media leads to their sedimentation in the aquatic system (Fig. 3a-c). A breakthrough curve was plotted for the change in the absorbance of the NPs at a specific wavelength $(320 \mathrm{~nm})$ against time. Photographs of the NP suspension were also captured in a time dependent manner that confirms the sedimentation of the NPs (Fig. 3d). The intensity of $\mathrm{TiO}_{2} \mathrm{NP}$ sedimentation was in the order: E3 medium > Dryl's buffer > MilliQ water. These results indicate that sedimentation of NPs in both media was initiated after $4 \mathrm{~h}$ and stopped at $24 \mathrm{~h}$ in the case of Dryl's buffer, while it continued up to $48 \mathrm{~h}$ in E3 medium. In Dryl's buffer, sedimentation was observed up to $24 \mathrm{~h}$ due to the formation of large aggregates at initial time points and no aggregates formed at later time points. However, in E3 medium, the NP aggregate formation continued up to $48 \mathrm{~h}$, hence sedimentation was observed up to $48 \mathrm{~h}$. The presence of HA inhibited the sedimentation of NPs to some extent in both media. A slight increase in the sedimentation of the NPs was also observed in MilliQ water in the absence of HA due to aggregation of the NPs.

Studies have demonstrated that HA prevents the aggregation of NPs in an aqueous suspension via their adsorption on the NP surface. ${ }^{29,30}$ In contrast, it has also been demonstrated that the presence of a higher salt concentration can induce NP aggregation even in the presence of HA. The stability of the NPs plays a critical role in their impact on organisms. The E3 medium and Dryl's buffer are frequently used in laboratory-based ecotoxicity experiments on zebrafish embryos and ciliated protozoans (e.g. Tetrahymena or Paramecium), respectively. The results obtained in the present study demonstrate that the aggregation and sedimentation behaviour of $\mathrm{TiO}_{2}$ NPs increased due to the

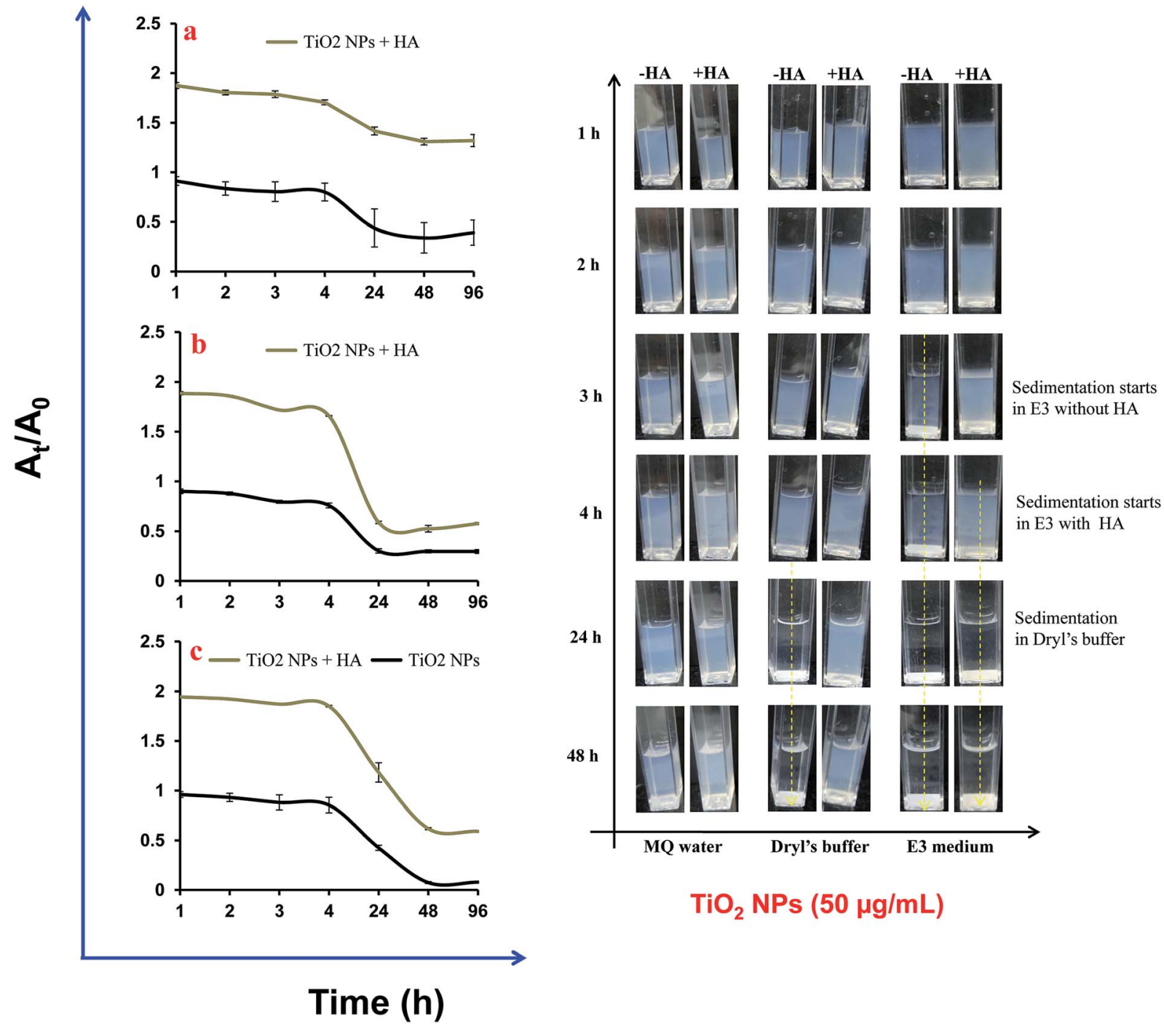

Fig. 3 Sedimentation of $\mathrm{TiO}_{2}$ nanoparticles in the different experimental buffers in the presence and absence of humic acid (HA). (a) MilliQ water, (b) E3 medium, (c) Dryl's buffer and (d) photographs of nanoparticles suspension up to $48 \mathrm{~h}$. 


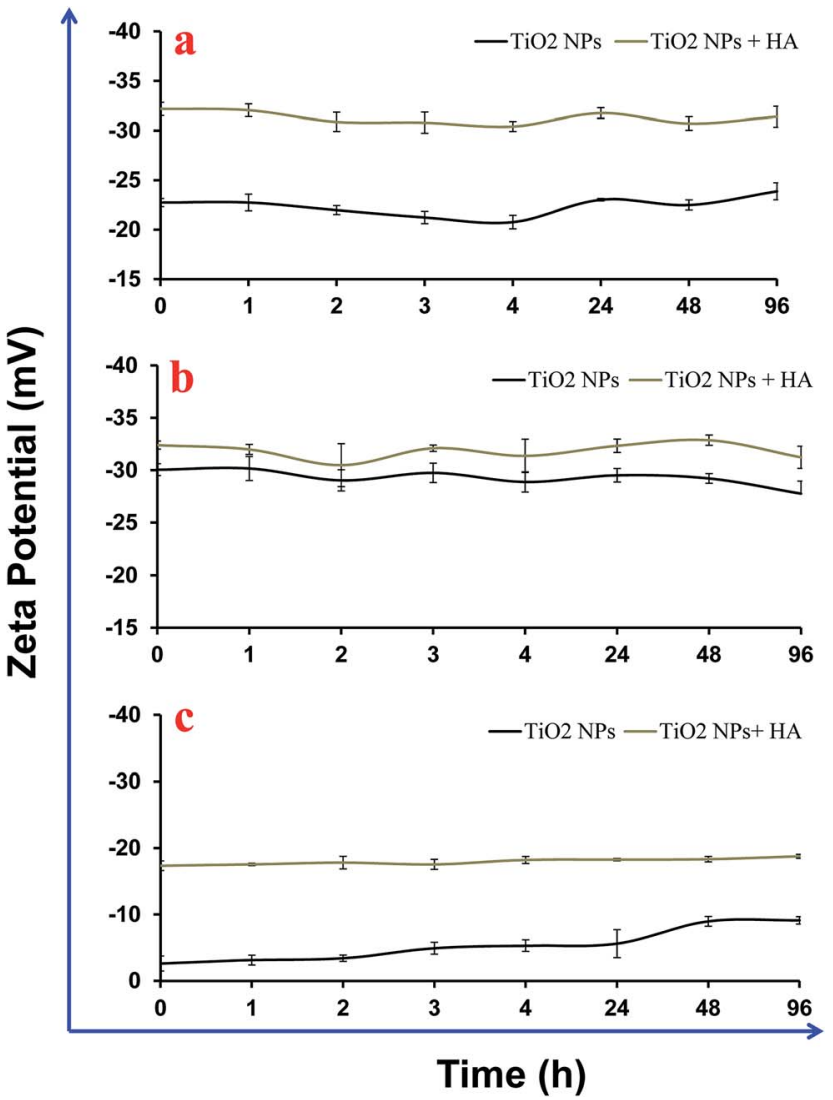

Fig. 4 Zeta potential of $\mathrm{TiO}_{2}$ nanoparticles $\left(50 \mu \mathrm{g} \mathrm{mL}^{-1}\right)$ in different experimental buffers in the presence and absence of humic acid (HA) $\left(10 \mu \mathrm{g} \mathrm{mL}^{-1}\right.$ ). (a) MQ water, (b) Dryl's buffer and (c) E3 media.

buffer used for ciliated protozoan to zebrafish. However, addition of HA to the experimental media prevented the aggregation of NPs to some extent. Therefore, our study demonstrates that the use of HA in ecotoxicity experiments will not only closely mimic environmental conditions but also help in conducting long term ecotoxicity assays.

\subsection{Adsorption and electro-kinetic interactions of HA with $\mathrm{TiO}_{2} \mathrm{NPs}$}

The adsorption of HA on $\mathrm{TiO}_{2}$ NPs was mainly driven by the complex interplay between electrostatic and steric interactions. Fig. 4 shows a change in the $\zeta$-potential of the $\mathrm{TiO}_{2}$ NPs after interaction with HA. The increased intensity of the negative $\zeta$ potential of the NPs varied between the experimental buffers and MilliQ water. In MilliQ water, the $\zeta$-potential of $\mathrm{TiO}_{2} \mathrm{NPs}$ was $-23 \mathrm{mV}$ and it increased to $-33 \mathrm{mV}$ in the presence of $\mathrm{HA}$ due its adsorption on the surface. The adsorption of $\mathrm{HA}$ on $\mathrm{TiO}_{2}$ NPs in MilliQ water could be mainly possible either due to the steric interactions or through ligand exchange. An increase in the magnitude of the $\zeta$-potential on the NP surface after binding of HA indicated the electrostatic interactions. Similarly, Jayalath et al. $2018{ }^{27}$ have shown that HA adsorbs on the surface of NPs under neutral $\mathrm{pH}$ conditions via electrostatic interactions between negatively charged NPs and HA of a different surface charge magnitude. In E3 medium, the surface potential of the $\mathrm{TiO}_{2}$ NPs was in the range of $-3.0 \mathrm{mV}$ to $-8.0 \mathrm{mV}$, and it increased to $-19 \mathrm{mV}$ immediately after addition of HA. In Dryl's buffer, the surface potential of the $\mathrm{TiO}_{2}$ NPs was $-30 \mathrm{mV}$, which increased to $-33.0 \mathrm{mV}$ after addition of HA. The change in the surface potential of the $\mathrm{TiO}_{2}$ NPs was not significant in Dryl's buffer after addition of HA, which might be due to poor binding as the presence of citrate ions interfered with the adsorption of HA on the surface of the $\mathrm{TiO}_{2}$ NPs. In E3 media the presence of electrolytes $\left(\mathrm{Ca}^{2+}, \mathrm{Na}^{+}, \mathrm{Mg}^{2+}\right.$ and $\left.\mathrm{K}^{+}\right)$increases the ionic strength of the suspension, which compresses the diffused layer present over the NPs and consequently reduces the $\zeta$-potential on the surfaces and diminishes the repulsions between NPs, and therefore promotes particle aggregation. However, addition of HA to this suspension to bind to the surface of the NPs induces electrostatic repulsion and reduces the aggregation of NPs. In E3 media, there was a range of mineral ions $\left(\mathrm{Ca}^{2+}\right.$, $\mathrm{Na}^{+}, \mathrm{Mg}^{2+}$ and $\mathrm{K}^{+}$) that were present that facilitated the electrostatic attractions between the NPs and HA in the suspension. Fig. 5 shows the fluorescence spectroscopy results
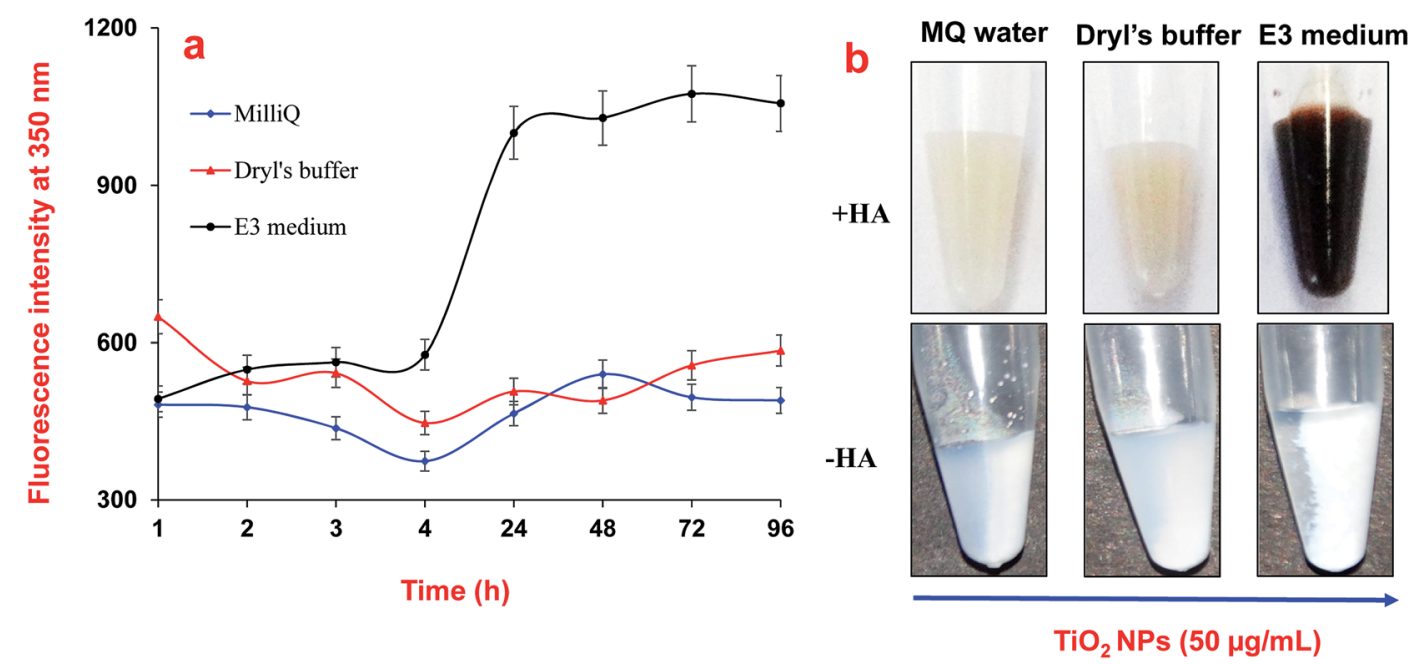

Fig. 5 Adsorption of humic acid $(\mathrm{HA})$ on the surface of $\mathrm{TiO}_{2}$ nanoparticles in $\mathrm{MQ}$ water and experimental buffers. (a) Fluorescence intensity of nanoparticles in the presence of humic acid and (b) photographs of settled nanoparticle suspensions in the presence and absence of humic acid. 
for the adsorption of $\mathrm{HA}$ on the surface of $\mathrm{TiO}_{2}$ NPs in the different buffers and MQ water. These results show a higher adsorption of HA on the NPs in the E3 medium compared to that in the MQ water and Dryl's buffer (Fig. 5a). The higher adsorption of HA in E3 medium was further confirmed in photographs captured after settling the NPs (Fig. 5b). A colour change was clearly observed with increasing adsorption of HA on the NPs in different experimental buffers. In previous studies, it has been shown that HA can influence the stability of $\mathrm{TiO}_{2}$ NPs through electrostatic repulsion, steric hindrance and bridging effects. ${ }^{28,31}$ Yang et al. (2009) showed that phenolic -OH of HA was responsible for its ligand exchange with $\mathrm{TiO}_{2}$ NPs. ${ }^{14}$

\subsection{Effect of HA on the toxicity of $\mathrm{TiO}_{2}$ NPs in Tetrahymena and Danio rerio embryos}

It was observed that NPs were internalised in cells within $1 \mathrm{~h}$ of exposure to $\mathrm{TiO}_{2} \mathrm{NPs}\left(100 \mu \mathrm{g} \mathrm{mL}^{-1}\right)$ in the presence and absence of HA (Fig. 6a-c). The black vesicles that appeared in the cytoplasm of Tetrahymena cells exposed to the $\mathrm{TiO}_{2} \mathrm{NPs}(50$ $\mu \mathrm{g} \mathrm{mL}{ }^{-1}$ ) were due to the internalization and accumulation of NPs in the cytoplasm. The internalization of NPs in Tetrahymena could occur through the phagocytosis process as demonstrated in previous studies. ${ }^{21,32}$ The adsorption of HA on the surface of the NPs may reduce their internalization in the Tetrahymena cells due to their higher negative charge intensity compared to bare $\mathrm{TiO}_{2}$ NPs. Tetrahymena images captured after exposure to bare $\mathrm{TiO}_{2}$ NPs (without HA) showed a large number of cytoplasmic vesicles compared to samples in the presence of HA (Fig. 6a-c). Hence, the presence of a lower number of vesicles in the cytoplasm indicated the reduced internalization of $\mathrm{TiO}_{2} \mathrm{NPs}$ in the presence of HA. Furthermore, the viability of Tetrahymena cells was also investigated after exposure to $\mathrm{TiO}_{2} \mathrm{NPs}$ in the presence and absence of HA. The results showed that $\sim 25 \%$ of the Tetrahymena cells were dead after exposure to bare $\mathrm{TiO}_{2} \mathrm{NPs}$ (without HA) for $24 \mathrm{~h}$ (Fig. 6d). However, no significant decline in the population of Tetrahymena cells was observed in the presence of HA after $24 \mathrm{~h}$ (Fig. 6e). This shows that HA was protecting the Tetrahymena cells from the toxic effects of the $\mathrm{TiO}_{2}$ NPs.

In Danio rerio embryos, the most significant effect of the addition of HA was the reversal of the viability in the embryos exposed to $\mathrm{TiO}_{2}$ NPs. The exposure of embryos to bare $\mathrm{TiO}_{2} \mathrm{NPs}$ (without $\mathrm{HA}$ ) affected the viability of $15 \%$ of the embryos as compared to the control. However, in the presence of HA, >95\% embryos were viable and healthy at each time point in the control and treatment groups (Fig. 7). Furthermore, the assessment of the hatching delay in the embryo after $\mathrm{TiO}_{2} \mathrm{NP}$ exposure showed $\mathrm{a} \sim 2 \mathrm{~h}$ delay in hatching in the presence or absence of HA. The continuous microscopic observation of NP exposed zebrafish embryos showed an adsorption of NPs over the chorion surface that prevented their interactions with the embryo (Fig. 7). The extensive adsorption of NPs over the chorion surface might also be a reason for the short delay in the hatching of the embryos. In previous studies, it has been shown that HA can cause a reversal effect on the toxicity of NPs. ${ }^{33}$ Hall et al. (2009) have shown that total organic carbon decreased the toxicity of NPs for Ceriodaphnia dubia. ${ }^{34}$ Lin et al. (2012) have also shown that an intracellular level of reactive oxygen species (ROS) generation by $\mathrm{TiO}_{2}$ NPs was significantly limited in the
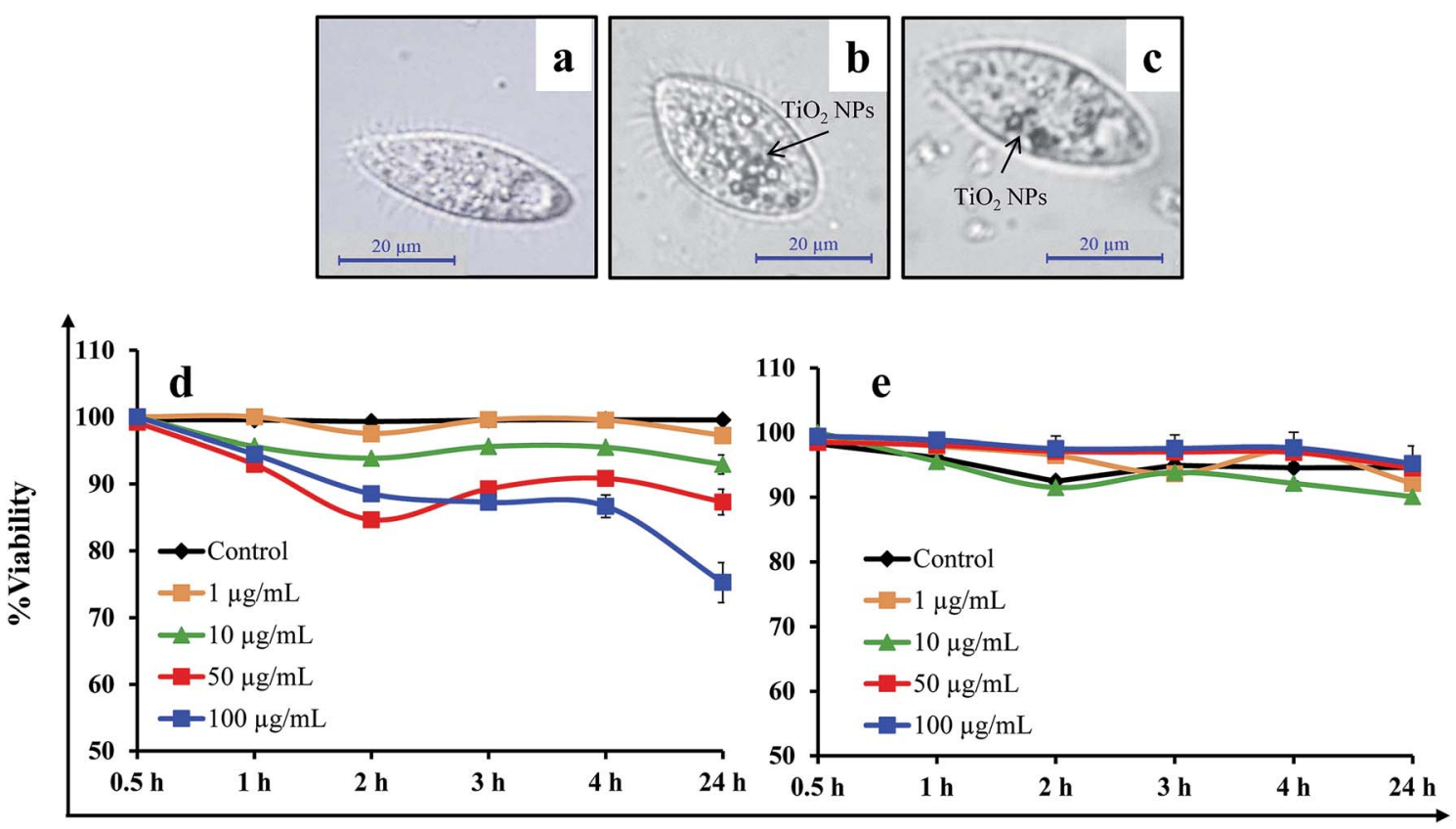

Time

Fig. $6 \mathrm{TiO}_{2}$ nanoparticle uptake and viability in Tetrahymena cells in the presence and absence of humic acid. (a-c) Optical micrographs showing $\mathrm{TiO}_{2}$ nanoparticles inside the cells: (a) control, (b) $\mathrm{TiO}_{2} \mathrm{NPs}$, (c) $\mathrm{TiO}_{2} \mathrm{NPs}+\mathrm{HA}$. (d and e) Viability of the cells after TiO 2 exposure, (d) without $\mathrm{HA}$ and (e) with $\mathrm{HA}$. 

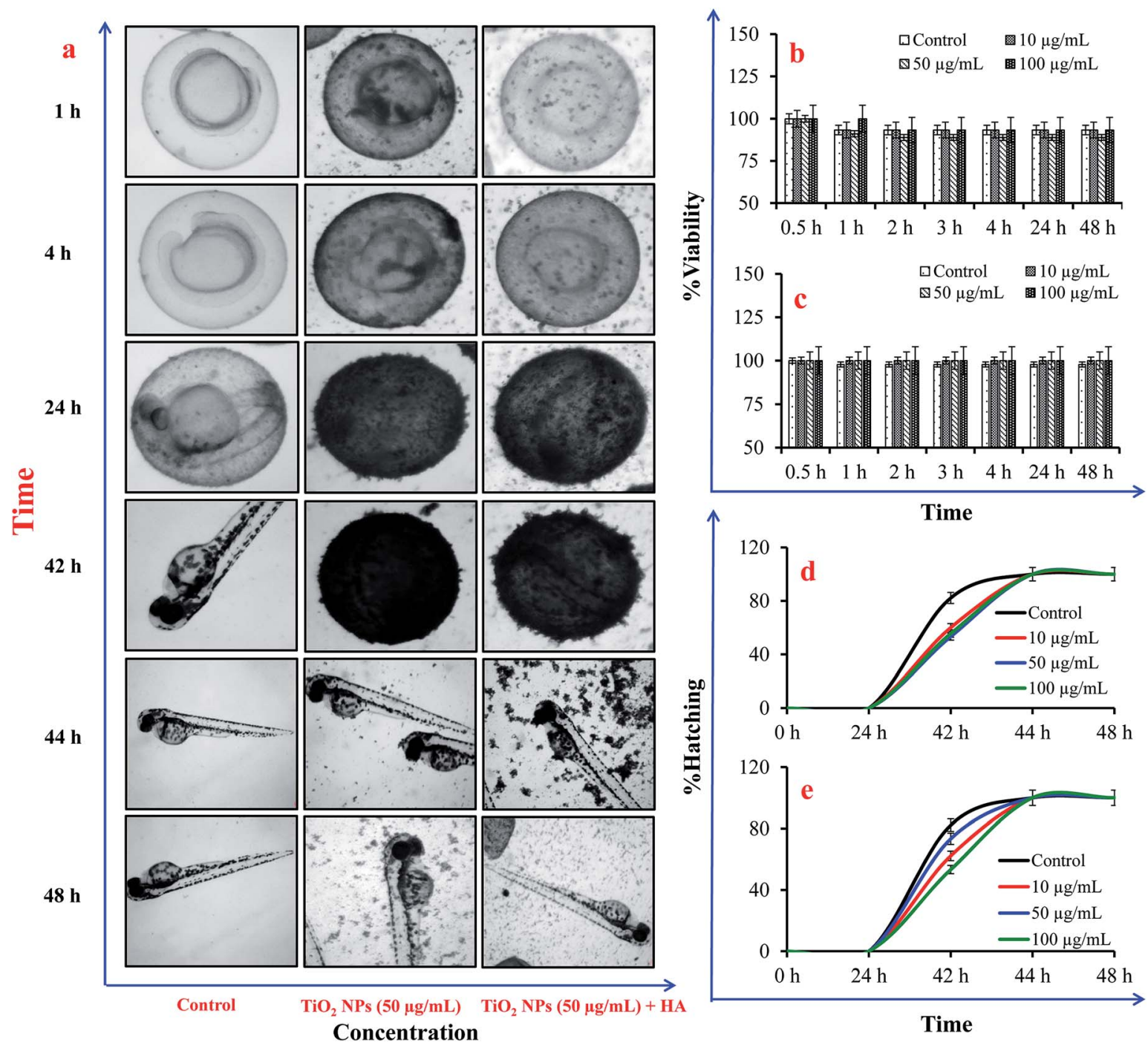

Fig. 7 Effects of humic acid on the viability and hatching of zebrafish embryos after exposure to $\mathrm{TiO}_{2}$ nanoparticles. (a) Photographs representing the adsorption of $\mathrm{TiO}_{2}$ nanoparticles on the chorion and the delayed hatching of embryos; (b) viability without humic acid; (c) viability with humic acid; (d) hatching of embryos without humic acid; (e) hatching of embryos with humic acid.

presence of HA, which consequently diminished their cytotoxicity. ${ }^{35}$ In contrast, Seitz et al. (2016) have demonstrated that in addition to the quantity, also the quality (including the aromaticity) of natural organic matter (NOM) influences the ecotoxicity of the $\mathrm{TiO}_{2} \mathrm{NPs}^{36}$ Yang et al. (2013) have shown that the presence of HA decreases the exposure to $\mathrm{TiO}_{2} \mathrm{NPs}$, but elevates their toxicity in the developing zebrafish under dark and simulated light conditions. ${ }^{37}$ In our zebrafish embryo toxicity studies, a $12 \mathrm{~h}$ light/14 h dark cycle was maintained to represent the actual toxicity outcome of $\mathrm{TiO}_{2}$ NPs under lightdark cycle conditions. However, in case of Tetrahymena toxicity, light exposure was not included because Tetrahymena cells were cultured and grown under dark conditions.

The present observation showed that the availability of such factors can influence the stability of NPs in experimental buffers, which is a major concern in conducting ecotoxicological assays using top order aquatic organisms e.g. Daphnia and zebrafish embryo. The findings of the present research will help regulatory agencies to design more reliable and stable ecotoxicological assays.

\section{Conclusions}

The observations of the present study demonstrate that humic acid increases the dispersion of $\mathrm{TiO}_{2}$ NPs in experimental buffers via adsorption on the surface of the NPs, mainly due to electrostatic interactions. The maximum aggregation was observed in the E3 medium even in the presence of HA. The intensity of $\mathrm{TiO}_{2}$ NP sedimentation was observed in the order: E3 media > Dryl's buffer $>$ MilliQ water. However, the ecotoxicity results for Tetrahymena pyriformis and Danio rerio showed that the presence of HA reduces the toxicity of $\mathrm{TiO}_{2} \mathrm{NPs}$. The study provides significant insights into the effects of humic acid on the experimental buffers extensively used in ecotoxicological assays. The finding suggests that the use of HA in 
ecotoxicological assays will facilitate the long-term risk assessment of NPs by increasing the stability.

\section{Conflicts of interest}

There are no conflicts to declare.

\section{Acknowledgements}

Funding received from the Department of Biotechnology, Government of India under the project "NanoToF: Toxicological evaluation and risk assessment on Nanomaterials in Food" (grant number BT/PR10414/PFN/20/961/2014) and DST SERB Project "Nanosensors for the Detection of Food Adulterants and Contaminants" (grant number EMR/2016/005286) is gratefully acknowledged. Financial assistance by the Gujarat Institute for Chemical Technology (GICT) for the establishment of a facility for environmental risk assessment of chemicals and nanomaterials is also acknowledged.

\section{References}

1 P. A. Holden, R. M. Nisbet, H. S. Lenihan, R. J. Miller, G. N. Cherr, J. P. Schimel and J. L. Gardea-Torresdey, Acc. Chem. Res., 2013, 46(3), 813-822.

2 A. Keller and A. Lazareva, Environ. Sci. Technol. Lett., 2014, 1, 65-70.

3 K. L. Garner and A. Keller, J. Nanoparticle Res., 2014, 16, 2503.

4 G. S. Gupta, V. A. Senapati, A. Dhawan and R. Shanker, J. Colloid Interface Sci., 2017, 495, 9-18.

5 R. A. French, A. R. Jacobson, B. Kim, S. L. Isley, R. L. Penn and P. C. Baveye, Environ. Sci. Technol., 2009, 43(5), 13541359.

6 A. A. Keller, H. Wang, D. Zhou, H. S. Lenihan, G. Cherr, B. J. Cardinale, R. Miller and Z. Ji, Environ. Sci. Technol., 2010, 44(6), 1962-1967.

7 R. F. Domingos, N. Tufenkji and K. I. Wilkinson, Environ. Sci. Technol., 2009, 43(5), 1282-1286.

8 A. P. Gondikas, F. von der Kammer, R. B. Reed, S. Wagner, J. F. Ranville and T. Hofmann, Environ. Sci. Technol., 2014, 48(10), 5415-5422.

9 X. Lin, J. Li, S. Ma, G. Liu, K. Yang, M. Tong and D. Lin, PLoS One, 2014, 9(10), e110247.

10 G. S. Gupta, A. Dhawan and R. Shanker, Chemosphere, 2016, 163, 242-251.

11 L. Clement, C. Hurel and N. Marmier, Chemosphere, 2013, 90(3), 1083-1090.

12 F. Seitz, M. Bundschuh, R. R. Rosenfeldt and R. Schulz, Aquat. Toxicol., 2013, 126, 163-168.

13 D. Xiong, T. Fang, L. Yu, X. Sima and W. Zhu, Sci. Total Environ., 2011, 409(8), 1444-1452.

14 K. Yang, D. Lin and B. Xing, Langmuir, 2009, 25(6), 35713576.
15 K. Ikuma, A. W. Decho and B. L. Lau, Front. Microbiol., 2015, 6, 591.

16 F. Loosli, P. L. Coustumer and S. Stoll, Water Res., 2013, 112.

17 J. B. Fellman, E. Hood and R. G. M. Spencer, Limnol. Oceanogr., 2010, 55(6), 2452-2462.

18 S. McDonald, A. G. Bishop, P. D. Prenzler and K. Robards, Anal. Chim. Acta, 2004, 527, 105-124.

19 Y. Cao, M. Conklin and E. Betterton, Environ. Health Perspect., 1995, 103(1), 29-32.

20 M. Mortimer, K. Kasemets and A. Kahru, Toxicology, 2010, 269(2-3), 182-189.

21 P. Ghafari, C. H. St-Denis, M. E. Power, X. Jin, V. Tsou, H. S. Mandal, N. C. Bols and X. S. Tang, Nat. Nanotechnol., 2008, 3(6), 347-351.

22 R. Werlin, J. H. Priester, R. E. Mielke, S. Kramer, S. Jackson, P. K. Stoimenov, G. D. Stucky, G. N. Cherr, E. Orias and P. A. Holden, Nat. Nanotechnol., 2010, 6(1), 65-71.

23 G. S. Gupta, A. Kumar, R. Shanker and A. Dhawan, Sci. Rep., 2016, 6, 31422.

24 K. Howe, M. D. Clark, C. F. Torroja, J. Torrance, C. Berthelot, M. Muffato, J. E. Collins, S. Humphray, et al., Nature, 2013, 496(7446), 498-503.

25 S. George, T. Xia, R. Rallo, Y. Zhao, Z. Ji, S. Lin, X. Wang, H. Zhang, B. France, D. Schoenfeld, R. Damoiseaux, R. Liu, S. Lin, K. A. Bradley, Y. Cohen and A. E. Nel, ACS Nano, 2011, 5(3), 1805-1817.

26 B. Xia, L. Zhu, Q. Han, X. Sun, B. Chen and K. Qu, Environ. Toxicol. Pharmacol., 2017, 50, 128-135.

27 S. Jayalath, H. Wu, S. C. Larsen and V. H. Grassian, Langmuir, 2018, 34(9), 3136-3145.

28 M. Zhu, H. Wang, A. A. Keller, T. Wang and F. Li, Sci. Total Environ., 2014, 487, 375-380.

29 Y. Li, C. Yang, X. Guo, Z. Dang, X. Li and Q. Zhang, Chemosphere, 2015, 119, 171-176.

30 M. Erhayem and M. Sohn, Sci. Total Environ., 2014, 468-469, 249-257.

31 S. Ghosh, H. Mashayekhi, P. Bhowmik and B. Xing, Langmuir, 2010, 26(2), 873-879.

32 M. Mortimer, A. Gogos, N. Bartolome, A. Kahru, T. D. Bucheli and V. I. Slaveykova, Environ. Sci. Technol., 2014, 48(15), 8760-8767.

33 I. Blinova, A. Ivask, M. Heinlaan, M. Mortimer and A. Kahru, Environ. Pollut., 2010, 158(1), 41-47.

34 S. Hall, T. Bradley, J. T. Moore, T. Kuykindall and L. Minella, Nanotoxicology, 2009, 3(2), 91-97.

35 F. Lin, J. Ji, Z. Long, K. Yang and F. Wu, Water Res., 2012, 46(14), 4477-4487.

36 F. Seitz, R. R. Rosenfeldt, M. Muller, S. Luderwald, R. Schulz and M. Bundschuh, Nanotoxicology, 2016, 10(10), 1415-1421.

37 S. P. Yang, O. Bar-Ilan, R. E. Peterson, W. Heideman, R. J. Hamers and J. A. Pedersen, Environ. Sci. Technol., 2013, 47(9), 4718-4725. 